University of Louisville

ThinkIR: The University of Louisville's Institutional Repository

$12-2016$

\title{
The impact of paroxysmal sympathetic hyperactivity following traumatic brain injury on intensive care unit length of stay and discharge disposition.
}

Kimberly S. Meyer

Follow this and additional works at: https://ir.library.louisville.edu/etd

Part of the Medicine and Health Sciences Commons

\section{Recommended Citation}

Meyer, Kimberly S., "The impact of paroxysmal sympathetic hyperactivity following traumatic brain injury on intensive care unit length of stay and discharge disposition." (2016). Electronic Theses and Dissertations. Paper 2565.

https://doi.org/10.18297/etd/2565

This Doctoral Dissertation is brought to you for free and open access by ThinkIR: The University of Louisville's Institutional Repository. It has been accepted for inclusion in Electronic Theses and Dissertations by an authorized administrator of ThinkIR: The University of Louisville's Institutional Repository. This title appears here courtesy of the author, who has retained all other copyrights. For more information, please contact thinkir@louisville.edu. 
THE IMPACT OF PAROXYSMAL SYMPATHETIC HYPERACTIVITY FOLLOWING TRAUMATIC BRAIN INJURY ON INTENSIVE CARE UNIT LENGTH OF STAY AND DISCHARGE DISPOSITION

By

Kimberly S Meyer

B.S.N., University of Louisville, 1992

M.S.N., University of Kentucky, 2002

\author{
A Dissertation \\ Submitted to the Faculty of the \\ School of Nursing, University of Louisville \\ In Partial Fulfillment of the Requirements \\ For the Degree of \\ Doctor of Philosophy \\ In Nursing \\ School of Nursing \\ University of Louisville \\ Louisville, KY \\ December, 2016
}


Copyright 2016 by Kimberly S. Meyer

All rights reserved 

THE IMPACT OF PAROXYSMAL SYMPATHETIC HYPERACTIVITY FOLLOWING TRAUMATIC BRAIN INJURY ON INTENSIVE CARE UNIT LENGTH OF STAY AND DISCHARGE DISPOSITION

\author{
By
}

Kimberly S. Meyer

B.S.N., University of Louisville, 1992

M.S.N., University of Kentucky, 2002

A Dissertation Approved On

October 25, 2016

By The Following Dissertation Committee:

Dissertation Chair, Sandra Smith, PhD, APRN, NNP-BC

Lee, Ridner, PhD, APRN, FNP-BC

Michael C. Park, MD, PhD

Muna Hammash, RN, PhD 


\section{DEDICATION}

This is dedicated to my smart and sassy daughter, Madison. Thank you for being the awesome daughter that you are so that I could be the person I needed to be. I couldn't have done this without your love and support. You have been my inspiration and my reason for pushing forward.

And now, it is time for sprinkles. 


\section{ACKNOWLEDGEMENTS}

First, I would like to thank Dr. Sandra Smith for the patience, guidance, and encouragement she has provided since I entered this program of study. I appreciate the extra time, aside from this dissertation, that she took to provide teaching advice when I was feeling almost overwhelmed.

In addition to my advisor, I would also like to thank the others on my committee: Dr. Lee Ridner, Dr. Muna Hammash, and Dr. Michael C. Park for stimulating thought and facilitating a workable project.

My sincerest gratitude goes to my long-time friend and mentor, Dr. Laura Mcilvoy. She piqued my interest in research when I was a relatively new nurse, and has fostered my professional development ever since. I would not have embarked on this journey of higher education without her as a role model.

And lastly, many thanks to my family, friends, and colleagues. Specifically, thanks for the dinners that served as necessary distractions or thought provoking discussions. And my fellow neurosurgery team, your belief in me, your encouragement, and your tolerance of my crazy schedule meant more than you will ever know. Without this never-ending support, it would have been easy to stray. 


\begin{abstract}
THE IMPACT OF PAROXYSMAL SYMPATHETIC HYPERACTIVITY

FOLLOWING TRAUMATIC BRAIN INJURY ON INTENSIVE CARE UNIT

LENGTH OF STAY AND DISCHARGE DISPOSITION
\end{abstract}

Kimberly S Meyer

October 25, 2016

Paroxysmal Sympathetic Hyperactivity (PSH) is a complication affecting a subset of patients with severe traumatic brain injury (TBI). It is associated with increased morbidity, longer lengths of stay, and delayed recovery (Perkes, Baguley, Nott, \& Menon, 2010). The most prevalent signs and symptoms of PSH include unprovoked tachycardia, tachypnea, hypertension, dystonia, and diaphoresis (Lemke, 2007). If untreated, PSH can lead to impaired cerebral blood flow, sub-endocardial damage, dehydration, malnourishment, and contractures (Lemke, 2007).

The purpose of this study was to determine the incidence of PSH in an American Level 1 trauma center, examine the differences between patients with severe TBI and those who develop PSH in terms of intensive care unit length of stay (ICULOS) and discharge disposition, and identify predictors of ICULOS in the patients with PSH. Data were abstracted from medical records $(\mathrm{N}=196)$ of patients with TBI. 
Results from this retrospective study indicate that there was no difference in intensive unit (ICU) length of stay in TBI patients with PSH compared to those without PSH. However, there was a significant difference in discharge disposition, so that patients without PSH were more likely to be discharged to a home or acute rehabilitation setting while those with PSH were more likely to be discharged to sub-acute rehabilitation or other high level medical care. Evaluation of physiologic parameters known to be abnormal in patients with $\mathrm{PSH}$ indicated that in this sample, only heart rate was a significant predictor of the development of $\mathrm{PSH}$. This suggests that is it reasonable to screen younger patients who exhibit signs of sympathetic hyperactivity after TBI for PSH. 
TABLE OF CONTENTS

PAGE

DEDICATION ...........................................................

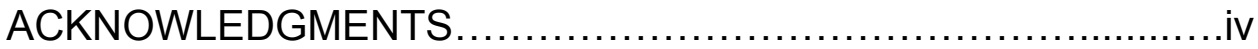

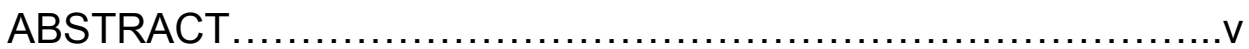

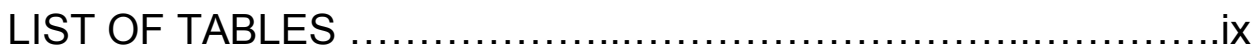

CHAPTER I: Introduction ...........................................

CHAPTER II: Understanding Paroxysmal Sympathetic Hyperactivity After Traumatic Brain Injury (Meyer, 2014): A Review of the Literature ....................................... 4

Overview.......................................... 4

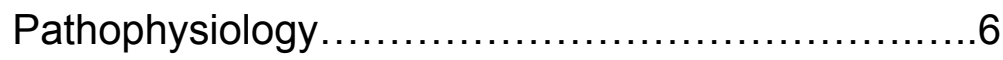

Treatment............................................

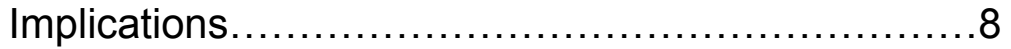

Conclusion.............................................

CHAPTER III: A Concept Analysis of Paroxysmal Sympathetic

Hyperactivity After Severe Traumatic Brain Injury

Introduction...........................................11

Background ........................................... 12

Surrogate Terms..................................... 13

Methods............................................... 
References, Antecedents, \& Consequences...........14

Model Cases........................................15

Interdisciplinary and Temporal Comparison...........16

Implications ..........................................17

Conclusions.............................................. 18

Figure 2 Theoretical Framework of $\mathrm{PSH} \ldots \ldots \ldots \ldots \ldots 19$

CHAPTER IV: The Impact of Paroxysmal Sympathetic Hyperactivity

Following Traumatic Brain Injury on Intensive Care Unit Length of Stay and Discharge Disposition.............20

Background......................................... 21

Methods................................................22

Procedures.............................................

Results............................................ 25

Discussion.............................................29

Limitations....................................... 31

Recommendations for Future Research..............32

CHAPTER V: Discussion and Conclusions.........................41

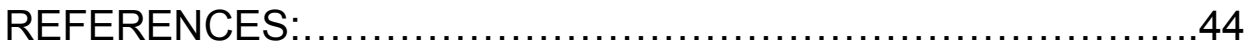

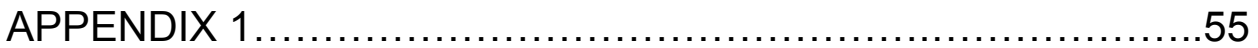

CURRICULUM VITAE ...........................................56 


\section{LIST OF TABLES}

TABLE

PAGE

1. Multi-system organ dysfunction associated with $\mathrm{PSH} \ldots \ldots \ldots \ldots 10$

2. Explanation Included and Excluded Traumatic Brain

Injury Cases.

3. Admission Characteristics of Patients with Severe

Traumatic Brain Injury Admitted to a Level 1 Trauma

Center Between 2010-2015..........................................35

4. Hospital Characteristics of Patients with Severe TBI on

Day 7

5. Hospital Characteristics of Patients with Severe TBI on

Day 14

6. Hospital Characteristics of Patients with Severe TBI on

Day 20

7. Discharge Characteristics of Patients with Expected TBI

Recovery and Those with PSH 


\section{CHAPTER I}

\section{INTRODUCTION}

Traumatic brain injury (TBI) affects over 1 million Americans annually (Centers for Disease Control and Prevention (CDC), 2010). Although only a small percentage of TBI is categorized as severe, this subgroup is at risk for prolonged hospital stays, persistent disability, and increased lifetime healthcare utilization resulting in significant burden to the healthcare system (CDC, 2010; Perkes et al., 2010; Whitmore et al., 2012). Acute care length of stay following uncomplicated severe TBI averages 18 days with hospital charges upward of $\$ 95,000$ per stay (Frankel et al., 2006). Up to one third of all severe TBI survivors may develop paroxysmal sympathetic hyperactivity (PSH), a condition that further complicates TBI recovery and lessens the likelihood for functional recovery (Hinson \& Sheth, 2012; Whyte et al., 2013). International literature suggests that those patients with PSH are at risk for prolonged lengths of stay in the intensive care unit and increased morbidity (Fernandez-Ortega et al., 2012).

Clinical experience suggests that delayed mobilization, longer intensive care unit length of stay (ICULOS), delayed coma emergence, and failure to qualify for acute brain injury rehabilitation are related to autonomic instability 
(Figure 1). Identification of predictors most influential in ICULOS may lead to earlier intervention and control of autonomic discharges. In turn, this might facilitate the earlier use of pharmacologic neuro-stimulation, rehabilitation and expedite discharge to high level brain injury recovery programs (Wheaton, Mathias, \& Vink, 2009; Whyte et al., 2013) as specialized care by neurotrauma specialists in acute care and rehabilitation is known to improve hospital outcome and the likelihood of community re-integration following TBI (Haas et al., 2009; Kramer \& Zygun, 2014; Whyte et al., 2013).

The purpose of this dissertation was threefold. First, the study aimed to determine the incidence of PSH in an American sample of severe TBI patients treated at a level 1 trauma center. Secondly, it sought to examine the effect of PSH on short-term outcome as measured by discharge destination. Lastly, the study explored the predictors that most influence ICULOS in patients with PSH.

The first manuscript is a review of literature. It indicates that PSH is a poorly understood condition and as a result, recognition and treatment of the symptom complexes is often delayed (Fernandez-Ortega et al., 2006). Brief, but frequent episodes of hemodynamic instability and physiologic distress manifested by shaking and profuse diaphoresis are the hallmarks of this condition (Lemke, 2007). Imaging studies in patients experiencing PSH often reveal evidence of diffuse axonal injury (Baguley, 2004; Baguley, 1999; Boeve, Wijdicks, Benarroch, \& Schmidt 1998a; Bower, 2010). Coma emergence and weaning from high dose opiates and sedatives are precursors frequently associated with the onset of signs and symptoms associated with $\mathrm{PSH}$. 
The second manuscript provides a concept analysis, comparing the sympathetic hyperactivity of PSH to the sympathetic surges seen in contrary cases of cerebral herniation syndrome. It identifies surrogate terms for PSH that were frequently used prior to the development of a standardized definition and nomenclature. Nursing surveillance was identified as a critical factor in the identification of PSH related symptoms.

The final manuscript presents findings from a retrospective study of 196 patients who had sustained a severe traumatic brain injury. The subjects were dichotomized into groups: those with $\mathrm{PSH}$ and those with normal TBI recovery trajectory. Although there was no difference in ICULOS between the two groups, those with PSH were less likely to discharge to acute rehabilitation than their counterparts without PSH. Heart rates at multiple time points were most predictive of the condition of $\mathrm{PSH}$.

Results from this dissertation suggest that patients with coma after TBI who develop unprovoked periods of tachycardia should be further screened for $\mathrm{PSH}$. Other findings indicate that those with higher discharge Glasgow Coma Scores, as seen in the TBI group, were associated with discharge to high-level brain injury rehabilitation. 
Figure 1

Theoretical Effect of PSH on TBI Recovery

\section{Theoretical Effect of PSH on TBI} Recovery

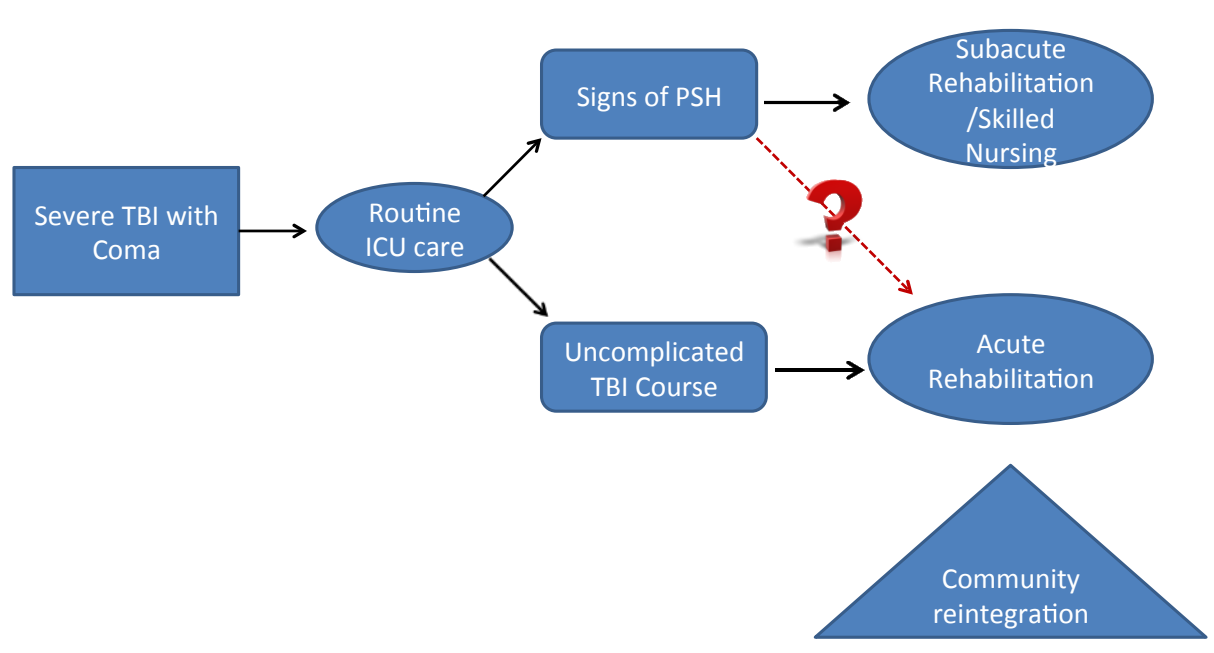

The expected recovery course of traumatic brain injury (TBI) follows the path from acute care to rehabilitation and community re-entry. The effects of paroxysmal sympathetic hyperactivity (PSH) may alter the recovery trajectory and delay or prohibit maximal recovery 


\section{CHAPTER II}

\section{UNDERSTANDING PAROXYSMAL SYMPATHETIC HYPERACTIVITY}

AFTER TRAUMATIC BRAIN INJURY (Meyer, 2014: Appendix 1)

\section{Overview}

Traumatic brain injury (TBI) affects 1.4 million Americans annually (CDC, 2010). Although only a small percentage of TBI is categorized as severe or comatose state, this subgroup of patients is at risk for prolonged hospital stays, persistent disability, and increased lifetime healthcare utilization (CDC, 2010). This sub-population of patients with TBI accounts for up to ninety percent of all TBI-related costs (CDC, 2010). Paroxysmal sympathetic hyperactivity (PSH) has been reported in up to $33 \%$ of patients with severe TBI (Hinson \& Sheth, 2012).

$\mathrm{PSH}$ has been discussed in the literature under a variety of terms. Early in the recognition of this phenomenon, the term diencephalic seizure was used (Penfield, 1929). However, later investigations failed to demonstrate epileptiform discharges on electroenecephalography so this term has seen a decrease in usage (Boeve et al., 1998a; Lemke, 2007). PSH later became known as dysautonomia, autonomic storming, sympathetic storming, and autonomic 
dysreflexia or hyper-reflexia (Baguley et al., 1999). The International Brain Injury Association has recently convened a consensus workgroup to clarify the nomenclature and diagnostic criteria for this entity. The proposed term from this consensus group is paroxysmal sympathetic hyperactivity (Baguley et al., 2014). To date, the vast majority of literature pertaining to $\mathrm{PSH}$ is found in the medical literature with attention paid to hypothesis of cause and pharmacologic management. With few exceptions, studies are limited to retrospective reviews, case studies, or small case series, thereby limiting their generalizability.

$\mathrm{PSH}$ is a poorly understood phenomenon with varied symptomatology. As a result, identification of the condition is often delayed (Hendricks, Heeren, \& Vos, 2010). Diagnosis is often one of exclusion, where other conditions with similar symptoms, such as infection or withdrawal, are ruled out. Brief, but frequent episodes of hemodynamic instability and physiologic distress are the hallmarks of this condition (Baguley et al., 2014; Lemke, 2007). Imaging studies in patients experiencing sympathetic storming often reveal evidence of diffuse axonal injury (Baguley et al., 2004; Boeve et al., 1998a). Coma emergence and weaning from high dose opiates and sedatives are precursors that are frequently associated with sign or symptom exhibition. Baguley et al., suggest that PSH is present if the following symptoms occur without other identifiable causes: hyperthermia, tachycardia, tachypnea, dystonia, hypertension, posturing and diaphoresis (Baguley et al., 1999; Lemke, 2007). Identification of these signs or symptoms often results in additional diagnostic work-up and increased medication requirements. 


\section{Pathophysiology}

$\mathrm{PSH}$ is thought to occur in stages. The first stage is often asymptomatic due to the heavy sedation and paralytics required for the acute management of intracranial hypertension and other trauma-related injuries. The second stage is characterized by the onset of symptom clusters and the third stage, by a decline in posturing and dystonia (Baguley et al, 1999). Baguley, Nott et al., (2009) and Baguley, Heriseanu et al., (2009) demonstrated that changes in heart rate variability associated with nociceptive stimuli accompany the onset of sympathetic storming. Retrospective reviews indicate that those with diffuse axonal injury on imaging studies are at highest risk for developing sympathetic storming (Baguley et al., 1999; Hendricks et al., 2010). Symptoms are thought to persist for months to years, with one study revealing a mean duration of 5 years post-injury (Baguley et al., 2009).

Various dissociation theories provide the theoretical framework for $\mathrm{PSH}$. These include those of structural disconnection where lesions in the mesencephalon cause disruptions in relay from the medulla/hypothalamus and the more widely accepted excitatory: inhibitory ratio (EIR) model where dysfunction of the diencephalic-brainstem inhibitory center that normally controls afferent stimulus processing in the spinal cord occurs (Baguley, 2008b;

Fernandez-Ortega et al., 2006; Lemke, 2007). Autonomic dysfunction is thought to result from functional disconnections related to traumatic damage involving the deep structures of the brain (Baguley, Heriseanu, Cameron et al., 2008). This is complicated by a relative reduction in functional dopaminergic activity (Baguley, 
Heriseanu, Cameron et al., 2008). As a result, there is unopposed adrenergic outflow with increased levels of circulating catecholamines (Baguley, Heriseanu, Cameron et al., 2008). Within this framework, there is an increase in the excitatory influences without a compensatory increase in inhibitory function, thus creating a tendency to develop an over-reaction to normally non-noxious stimuli (Baguley, Heriseanu, Nott et al., 2009; Baguley, Nott, Slewa-Younan et al., 2009). Multisystem organ dysfunction can follow if the condition is untreated.

\section{Treatment}

There is no accepted treatment algorithm for the management of PSH. Treatment is aimed at mitigating signs and symptoms to decrease associated adverse events such as cardiac hypertrophy, dehydration, muscle wasting, contractures, and delayed recovery which contribute to increased morbidity (Table 1). Multiple medications are often required to successfully control the multiple symptoms. Dopaminergic agents, specifically bromocriptine, have been shown to decrease body temperature and sweating (Bullard, 1987; Rossitch \& Bullard, 1988; Russo \& O'Flaherty, 2000). Alpha-agonists such as clonidine act to decrease heart rate and blood pressure (Payen, Quentin, Plaisance, Chiron, \& Lhoste, 1990; Russo \& O'Flaherty, 2000; Patel et al., 2012). GABA agonists are also useful in some cases. Baclofen can be given enterally or intrathecally. Intrathecal baclofen significantly reduces symptoms at substantially lower doses and subsequently, less toxicity (Cuny, Richer, \& Castel, 2001; Becker, Benes, Sure, Hellwig, \& Bertanlanffy, 2000). Gabapentin is thought to act on the dorsal horn of the spinal cord and in one small study, reduced the need for concomitant 
medications (Baguley, Slewa-Younan, et al., 2007). Opiates and non-selective beta-blockers have also been used (Baguley et al., 2004; Bullard, 1987).

In cases of medication failure, a case series of six patients demonstrated that hyperbaric oxygen (HBOT) controlled autonomic discharges and posturing in the sub-acute TBI phase (Lv et al., 2011). However, this treatment modality is of limited utility as there are an inadequate number of facilities with HBOT capabilities and the duration of therapy is prohibitive. Large experimental studies to validate the findings in these smaller studies are challenging due to difficulties in early identification of PSH and the relatively small number of qualifying patients.

\section{Implications}

Early identification and treatment of PSH is critical to facilitate recovery from traumatic brain injury and avoid permanent organ dysfunction. Expensive diagnostic testing is rarely warranted. Instead, the observational and analytical skills employed by most ICU nurses are more useful in recognizing PSH. In addition to communication of findings in order to facilitate diagnosis and treatment, nursing surveillance also affords the opportunity to identify and therefore potentially mitigate triggers. A final contribution of nursing involves family and caregiver teaching. In this role, the nurse explains the concept of $\mathrm{PSH}$, along with its causes and treatment, thereby aiding the family member to better cope with the paroxysms that can be very frightening or chaotic to watch.

Early initiation of symptom specific therapy, although beyond the scope of this paper, is thought to decrease complication rates and ICU length of stay and 
to facilitate recovery (Hinson \& Sheth, 2012). Understanding both the cause and complexity of these storming (PSH) events will lead to appropriate diagnosis and improved therapeutic interventions.

\section{Conclusion}

PSH should be considered when patients emerging from coma exhibit multiple, concurrent symptoms of sympathetic over-activity: hyperthermia, posturing, dystonia, tachycardia, tachypnea, diaphoresis, or hypertension. Nurses play a pivotal role in identifying the condition of $\mathrm{PSH}$, observing and mitigating the triggers which precipitate the event, communicating patient needs to the interdisciplinary team and finally, educating the family/caregivers. Ongoing research should include efforts to develop scales to document the frequency and severity of these paroxysmal episodes and treatment algorithms to guide the clinician in the management of PSH. 


\section{Table 1}

Multi System Dysfunction Associated with Sympathetic Storming/Paroxysmal Sympathetic Hyperactivity (PSH).

\begin{tabular}{|c|c|}
\hline Organ System & Sign/Symptom \\
\hline Cardiovascular & $\begin{array}{l}\text { - } \text { Tachycardia } \\
\text { - Increased contractility } \\
\text { - Increased cardiac output }\end{array}$ \\
\hline Pulmonary & $\begin{array}{l}\text { - Tachypnea } \\
\text { - Bronchial dilation }\end{array}$ \\
\hline Eyes & - Pupillary dilation \\
\hline Gastrointestinal & $\begin{array}{l}\text { - } \text { Decreased GI motility } \\
\text { - Increased tube feed residual } \\
\text { - Ileus }\end{array}$ \\
\hline Musculoskeletal & $\begin{array}{l}\text { - } \text { Dystonia } \\
\text { - Posturing } \\
\text { - Contractures } \\
\text { - Spasticity }\end{array}$ \\
\hline Adrenal & $\begin{array}{l}\text { - Increased release of epinephrine } \\
\text { - Increased release of } \\
\text { norepinephrine }\end{array}$ \\
\hline
\end{tabular}


CHAPTER III

A CONCEPT ANALYSIS OF PAROXYSMAL SYMPATHETIC HYPERACTIVITY AFTER SEVERE TRAUMATIC BRAIN INJURY

\section{Overview}

Paroxysmal Sympathetic Hyperactivity $(\mathrm{PSH})$ is a phenomenon that is seen following a variety of neurological insults. In particular, it is well described following severe traumatic brain injury (TBI) (Baguley, 2008a; Baguley et al., 2006; Baguley, Nott et al., 2009; Boeve et al., 1998a; Lv et al., 2011). PSH consists of paroxysmal sympathetic discharges (Baguley, 2008b; Lemke, 2007) thought to result from an imbalance in afferent and efferent systems which alter the normal excitatory:inhibitory ratio (EIR) of the autonomic nervous system (Baguley, 2008b). This results in a constellation of symptoms, including tachycardia, hypertension, diaphoresis, hyperthermia and spontaneous posturing. These paroxysms occur at intervals throughout the day, usually in response to a stimulus or "trigger". Once a stimuli manifests, the patient with PSH exhibits the multiple symptoms of physiologic distress. During these episodes, additional nursing care may be hampered in an effort to avoid additional problems such as hypertensive crisis, improper positioning or a prolonged hyperadrenergic state. 


\section{Background}

PSH has been reported in up to $33 \%$ of patients with severe TBI (Hinson \& Sheth, 2012) and is thought to increase morbidity and mortality related to TBI (Fernandez-Ortega et al., 2006). To date, the vast majority of literature pertaining to $\mathrm{PSH}$ is found in the medical literature with attention paid to hypothesis of cause and pharmacologic management. However, little is stated regarding the role of the nurse in the recognition and management of $\mathrm{PSH}$. Clarification of this concept will aid the nurse in identifying the phenomena and guide interventions to improve the symptomatology and thereby outcomes.

Rogers (2000) evolutionary method of concept analysis was used to evaluate the concept of PSH. This eight-step process allows for in depth investigation of the term, with interval development of model cases used to describe the phenomena of PSH, formerly known as sympathetic storming. The concept of PSH can also be considered in the theoretical context: the theory of unpleasant symptoms (Lenz, Pugh, Milligan, Gift, \& Suppe, 1997; Lenz, Suppe, Gift, Pugh, \& Milligan, 1995). This nursing theory was initially used to discuss the multiple symptoms (fatigue and dyspnea) in post-partum and COPD patients (Lenz et al., 1995). More recently, it has been used to investigate multiple symptoms in Alzheimer's disease (Hutchinson \& Wilson, 1998) and multiple sclerosis (Motl, 2014). In short, this middle range theory can be used to investigate the inter-relationships of multiple related symptoms as they exist in a 
single disease process, and subsequently their effect on functional and cognitive performance (Lenz, Gift, Pugh \& Milligan, 2012).

\section{Surrogate Terms}

PSH has been discussed in the literature under a variety of terms. Early in the recognition of this phenomenon, the term diencephalic seizure was used. However, later investigations failed to demonstrate seizure activity on electroenecephalography so this term became obsolete (Boeve et al., 1998a; Lemke, 2007). It later became known as dysautonomia, autonomic storming, sympathetic storming, and autonomic dysreflexia or hyper-reflexia. The International Brain Injury Association recently convened a consensus workgroup to clarify the nomenclature and diagnostic criteria for this entity. The proposed term is paroxysmal sympathetic hyperactivity (Baguley, 2013) although the term sympathetic storming maintains a clinical stronghold.

\section{Methods}

A literature review was conducted using MEDLINE and CINAHL. No time limitations were specified. A search for the widely used clinical term of sympathetic storming combined with severe traumatic brain injury was performed. This search yielded only four articles. These articles and their corresponding reference lists were reviewed and additional search terms of diencephalic seizures, dysautonomia, autonomic storming, autonomic hyporeflexia, paroxysmal sympathetic hyperactivity, and autonomic hyper-reflexia were identified. These terms were also combined with traumatic brain injury to eliminate other similar autonomic conditions associated with congenital birth 
defects, spinal cord injury, and other non-traumatic brain pathology. PSH and its surrogates were also combined with the term unpleasant symptoms, yielding no further results. The website for the Brain Injury Association of America was also queried as they were known to have a workgroup focusing on autonomic dysfunction. Additional query of the World Wide Web failed to produce any articles of sufficient quality to warrant inclusion. In sum, twenty articles specific to the concept of PSH were included.

\section{References, Antecedents, and Consequences}

$\mathrm{PSH}$, frequently called sympathetic storming, can be likened in some ways to the more well-known phenomenon, a thunderstorm. The thunderstorm occurs when in the presence of sufficient atmospheric moisture; warm air and cooler air collide, thus creating an unstable environment. Subsequently, the "symptoms," thunder, lightning, wind gusts, and rain occur. In some cases, thunderstorms continue to move through a geographic area until the stimulus, usually water vapor has diminished (Anonymous, 2012). Like a thunderstorm, these sympathetic storms or paroxysms begin rapidly with minimal stimuli, yielding multiple symptoms while disrupting normal homeostasis of the body. Once the trigger is removed or afferent input blunted, the "storm" can then dissipate.

Acquired brain injury, specifically severe traumatic brain injury (TBI), is an absolute antecedent for the development of PSH. The presence of diffuse axonal injury on imaging studies has previously been associated with PSH (Baguley et al., 2004; Boeve et al., 1998a). Initial symptoms of PSH are frequently blunted by the use of opiates and sedatives in the intensive care unit. As these medications, 
are weaned, symptoms may be become prevalent. Baguley suggests that PSH is present if 5 or more of the following symptoms are present without other identifiable causes: hyperthermia, tachycardia, tachypnea, dystonia, hypertension, posturing and diaphoresis (Baguley et al., 2014). No further attributes were identified).

If the symptoms are unrecognized or misattributed to other conditions by the nurse or medical team, a delay in appropriate treatment may result. A lag in condition specific treatment for these storming episodes can result in dysfunction of multiple organ systems. These consequences can result in permanent organ injury (i.e. myocardial infarction), prolonged intensive care unit length of stay, increased health care costs, and delayed recovery (Hinson \& Sheth, 2012).

\section{Model Cases}

\section{Model Case}

$\mathrm{SM}$ is a 24-year-old male who was involved in a motor vehicle collision. He sustained a severe traumatic brain injury with an initial Glasgow Coma Score of 5 . He required mechanical ventilation and intracranial pressure management for 10 days following his injury. Since weaning from the ventilator and sedation, he has developed periods of labile vital signs and other evidence of autonomic dysfunction. During these episodes, his heart rate (HR) is 150 beats per minute, blood pressure (BP) 170/92 mmHg, respiratory rate (RR) 38 breaths per minute, and he requires frequent linen changes due to profuse diaphoresis. At times, he exhibits extensor tone, which makes positioning difficult. 


\section{Contrary Case}

TS is an 18 year old female who has been hospitalized for 24 hours following a penetrating brain injury. On admission, she had no corneal reflexes and fixed and dilated pupils. Her Glasgow Coma Score was 3. Most recent vital signs reveal HR 170 beats per minute, BP 200/98 mmHg, RR 12 breaths per minute per ventilator and intracranial pressure $(\mathrm{ICP}) 70 \mathrm{~cm} / \mathrm{H} 20$. She has no motor response to noxious stimuli and no spontaneous respirations. While this patient is in a hyperadrenergic state, this scenario is more consistent with cerebral herniation syndrome than paroxysmal sympathetic hyperactivity. Interdisciplinary and Temporal Comparisons

Nursing surveillance (Kelly, 2011) is conducted throughout the critical phases of TBI recovery. It is through this surveillance, observing abnormal vital signs and physical findings and interpretation of their meaning that the diagnosis of PSH is suspected. Communication of these findings to the medical staff is pivotal in confirming PSH as many of the symptoms (i.e. posturing, diaphoresis) are not readily ascertained from scanning the nursing notes or vital signs in the medical record. Even if identified, it is difficult to reconstruct the PSH or "storming" episode. Furthermore, the direct communication between nurses and medical staff remain critical with the increasing number of patient handoffs due to work hour restrictions, and transfer of care from specialists in neurological care to general practitioners who are less familiar with the complications associated with TBI. Another method of relaying the variability in the patient condition involves interdisciplinary team rounds. This method of communication has been shown to 
improve outcomes in high-risk populations (Kauh, Polak, Hazelett, Hua, \& Allen, 2005).

\section{Implications}

Early identification and treatment of PSH is critical to facilitate recovery from traumatic brain injury and avoid permanent organ dysfunction. Expensive diagnostic testing is rarely warranted. Instead, the observational and analytical skills employed by most ICU nurses are most useful. In addition to communication of findings in order to facilitate diagnosis and treatment, nursing surveillance also affords the opportunity to identify and therefore, potentially mitigate triggers (Figure 2). These triggers or activities that may stimulate the sympathetic activity vary by patient and may be divided into external and internal stimuli. External triggers are commonly thought to be necessary nursing activities such as suctioning or positioning, caressing by the family, or excessive auditory stimulation (i.e. radio, monitor alarms) (Lemke, 2003; 2007). However, even with astute observation, a trigger is not always immediately identified and internal stimuli such as pain, constipation, or obstructed urinary catheters should be considered. A final contribution of nursing involves family and caregiver teaching. In this role, the nurse explains the concept of sympathetic storming or $\mathrm{PSH}$, its causes, and treatment, thereby aiding the family member to better cope with the paroxysms (or "storms") that can be very frightening or chaotic to watch.

Early initiation of symptom specific therapy, although beyond the scope of this paper, is thought to decrease complication rates, ICU length of stay, and facilitate recovery (Hinson \& Sheth, 2012). Understanding both the cause and 
complexity of these PSH events, will lead to improved diagnosis and therapeutic interventions.

\section{Conclusion}

PSH should be considered when patients emerging from coma exhibit multiple, concurrent symptoms of sympathetic over-activity: hyperthermia, posturing, dystonia, tachycardia, tachypnea, diaphoresis, or hypertension. Nurses play a pivotal role in identifying the condition of $\mathrm{PSH}$, observing and mitigating the triggers which precipitate the event, communicating patient needs to the interdisciplinary team, and finally, educating the family/caregivers. Ongoing research should include efforts to develop scales to document the frequency and severity of these paroxysmal episodes, as well as determine the impact of aggressive nursing care on the outcomes of this phenomenon. 


\section{CHAPTER IV}

\section{THE IMPACT OF PAROXYSMAL SYMPATHETIC HYPERACTIVITY \\ FOLLOWING TRAUMATIC BRAIN INJURY ON INTENSIVE CARE UNIT \\ LENGTHOF STAY AND DISCHARGE DISPOSITION}

\section{Overview}

The purpose of this study was to determine the incidence of Paroxysmal Sympathetic Hyperactivity (PSH) in an American level 1 trauma center, and examined the differences between patients with severe TBI and those who develop PSH in terms of intensive care unit length of stay (ICULOS) and discharge disposition. Additionally, the study identified predictors of ICULOS in the patients with $\mathrm{PSH}$.

$\mathrm{PSH}$ is a complication affecting a subset of patients with severe traumatic brain injury. It is associated with increased morbidity, longer lengths of stay, and delayed recovery (Perkes, Baguley, Nott, \& Menon, 2010). The most prevalent signs and symptoms of PSH include unprovoked tachycardia, tachypnea, hypertension, dystonia, and diaphoresis (Lemke, 2007). There has also been an association with prolonged pyrexia (Rabenstein, 2007). If untreated, PSH can lead to impaired cerebral perfusion, myocardial damage, dehydration, malnourishment, and contractures (Lemke, 2007). 


\section{Background}

Traumatic brain injury (TBI) is a public health crisis with over 1 million new cases in the United States annually (Corrigan, Selassie, \& Orman, 2010; CDC, 2010). Approximately ten percent of these injuries result in severe TBI with prolonged periods of coma and post-traumatic amnesia (Bruns \& Hauser, 2003). The impaired neurologic function associated with severe TBI requires prolonged hospitalizations, invasive monitoring and intensive neuro-rehabilitation and in many cases, can result in life-long disability. As a result, the small percentage of patients with severe TBI, utilize the biggest proportion of TBI resources and healthcare dollars (CDC, 2010; Mcllvoy, 2001). An even smaller subset of severe TBI can develop paroxysmal sympathetic hyperactivity (PSH) (Baguley, 2008a; Baguley et al., 2009; Hinson \& Sheth, 2012). This condition is characterized by periods of excessive activation of the sympathetic nervous system, resulting in intermittent episodes of hypertension, tachycardia, tachypnea, diaphoresis, and abnormal motor responses (Fernandez-Ortega et al., 2012; Gao, Pollock, \& Hinson, 2014; Hinson \& Sheth, 2012; Lemke, 2003; 2007). Known to mostly affect younger patients and those with diffuse rather than localized brain injury, PSH symptoms can last for days to years (Baguley et al., 2006; FernandezOrtega et al., 2012; Lv et al., 2011).

Because patients with PSH exhibit periods of physiologic distress, it is postulated that they have longer stays in the intensive care unit (ICULOS) and are more likely than other TBI patients to require ongoing medical care and increased resource utilization. A retrospective study was performed to determine 
the differences in ICULOS and discharge dispositions from acute care. The physiologic parameters of heart rate (HR), systolic blood pressure (SBP), temperature $(T)$, respiratory rate (RR), and free water requirements at specific time points during the hospital stay were explored to determine which factor most influenced ICULOS.

\section{Methods}

A retrospective design of medical record review was used. A multivariate analysis of variance (MANOVA) was performed to determine group differences in the following parameters: heart rate (HR), systolic blood pressure (SBP), temperature $(T)$, respiratory rate $(R R)$, intracranial pressure $(I C P)$ and free water requirements. In addition to age and GCS, physiologic factors showing statistical significance between groups were entered as predictors in a multiple regression model to determine factors most predictive of ICULOS, thereby facilitating a clinically relevant starting point for treatment of $\mathrm{PSH}$.

\section{Measures}

Variables associated with PSH were identified from previous literature. Physiologic parameters were abstracted from the vital sign flow sheet record in the electronic medical record. The highest and lowest recorded values in a 24 hour period where captured for each parameter. The first variable, HR was measured in beats per minute as auto-recorded by Hewlett-Packard telemetry. SBP, measured in $\mathrm{mm} \mathrm{Hg}$ was captured preferentially from arterial line monitoring, In the absence of invasive SBP monitoring, values were captured from automatic non-invasive blood pressure cuff monitoring using Hewlett- 
Packard monitoring devices. Temperature, measured in degrees Fahrenheit was captured from the vital sign registry. Location of temperature measurement was not routinely identified. When a ventriculostomy was in place, ICP values in $\mathrm{cm}$ of water were obtained using strain-gauge catheters with Hewlett Packard monitoring. When measured by a parenchymal bolt, ICP was obtained from Integra ${ }^{\circledR}$ Camino ${ }^{8}$ technology. Free water requirements were measured as the amount of water in milliliters required in a 24 -hour period to maintain normal serum sodium, blood urea nitrogen, and serum creatinine values. This information was abstracted from the medication administration record.

Length of stay was calculated in days. ICULOS was calculated by subtracting the day transferred out of ICU from the day of admission. Hospital LOS was calculated by subtracting the day of discharge from the day of admission. Discharge disposition, i.e. the level of care the patient was transferring to following acute hospitalization, was identified from the nursing narrative and care coordination notes. The GCS was identified from the neurosurgery consultation and nursing notes. The Injury Severity Score (ISS) incorporates injury to different body parts to a summed score representing the overall injury severity. Higher ISS scores are associated with higher morbidity and mortality. The Abbreviated Injury Score- head (AIS-head) was captured as it reflects the injury severity specific to the head. The ISS ranges from 0-75 and AIS- head from 1-6; higher scores on both scales are indicative of more severe injury. The ISS and AIS-head were calculated at hospital discharge by the trauma registrars and were obtained directly from the Trauma Institute database. 


\section{Procedures}

Following approval of the local institutional review board (IRB), the trauma database was queried. A list $(N=620)$ was generated that included all trauma patients treated at a level 1 trauma center from the years 2010- 2015 presenting with evidence of a head injury and admission Glasgow Coma Score $\leq 8$, indicating coma or severe TBI. The principal investigator reviewed each chart for inclusion/exclusion criteria. This yielded 196 cases meeting the inclusion criteria: severe TBI as defined by Glasgow Coma Score (GCS 4-8) and age greater than or equal to 16 at time of hospital admission. Cases were excluded if the postresuscitation GCS was 3 or $>8$, there was concomitant spinal cord injury, presence of bilateral non-reactive pupils, orders for comfort measures only within the first 5 days of hospitalization, or there was the absence of a mechanical traumatic mechanism. A large number of cases were excluded as the admission GCS was influenced by the use of neuromuscular blocking agents or high dose sedatives (Table 2). Included cases were dichotomized into two groups by the principal investigator: those with documented $\mathrm{PSH}$ or strong suspicion based on chart review (PSH group, $n=45$ ) and those without evidence of PSH (TBI group, $n=151)$. Data were extracted from the medical records on patient hospital days $1,7,14,20$ and the day of discharge.

\section{Data Analysis}


Analysis was performed using SPSS v 22. Student's t-test was used to assess normally distributed data for differences in age, admission/discharge GCS, and overall ISS. Similarly, ANOVA was used to evaluate for differences in mechanism of injury and AIS-H and discharge disposition. Given appropriate correlations of the physiologic parameters, a MANOVA was used to assess for any between group differences. Statistically significant parameters were included in the multiple regression analysis using hierarchal entry to identify which factors were most likely to predict ICULOS. Not all patients required hospitalization through day 20. Therefore, every patient underwent analysis of physiologic parameters at days one and seven, but those with early discharges were removed from further analysis after their discharge date to avoid the appearance of excessive missing data.

\section{Results}

\section{Admission Characteristics}

There was no difference in admission GCS between groups (TBI versus $P S H)$; the mean of both groups was $6(p=0.143)$. Age at time of injury was significantly different $(p=.002)$ between groups (Table 3 ). Patients exhibiting PSH were younger (mean age 28 years, SD 10.7) compared to the TBI group (mean age 38 years, SD 15.9). Patients with PSH had significantly worse overall ISS (mean 32.9, SD 8.63) compared to the TBI group (mean 29.2, SD 10, $p=$ 0.012) although the severity of injury specific to the head was no different (AIS-h $p=0.114)$. High velocity injury from motor vehicle collision was the predominant 
mechanism of injury in both groups (TBI- $64 \%$ versus $\mathrm{PSH} 82 \%, p=0.079$ ) (Figure 3).

\section{Patient Characteristics During Hospital Stay}

Day 7 analyses included all 196 patients. Patients were dichotomized to the TBI group $(n=151)$ and PSH group $(n=45)$ based on the presence or absence of PSH symptoms. Subject attrition due to early discharge resulted in 181 patients included in the day 14 analyses, and 137 patients in the day 20 analyses.

Monitoring of intracranial pressure (ICP) was done at the discretion of the attending neurosurgeon. As a result, 81 patients had ICP monitoring on day 1 , with 87 patients monitored on day 7 and only 33 patients required ongoing monitoring on day 14 . Of those with ICP availability, there was a minor clinical, but statistically significant difference in mean ICPs between groups on day 1 but not on subsequent days $(p=.001$ with TBI mean $16.11 \mathrm{~cm} \mathrm{H} 20$, SD 7.82 and PSH mean 22.83, SD 7.99).

The amount of free water $(\mathrm{mL})$ administered in order to maintain a normal sodium level was recorded as a marker of hydration status. This was found to only be significant on the day of discharge. Patients with PSH required a mean of $829 \mathrm{~mL}$ (SD 789mL) while patients without PSH required only $366 \mathrm{~mL}$ (SD 479 $m L)$. Many of the patients in the standard TBI group $(n=72)$, required no supplemental free water at hospital discharge. 
Prior to analysis, statistical assumptions were assessed. Independence was confirmed as patients were assigned to only one group (TBI or PSH). Levene's tests were non-significant indicating similar variances between groups. Evaluations of mechanism of injury and discharge dispositions initially failed to show a normal distribution, therefore, groups were collapsed to improve normality.

Pearson correlation coefficients $(r)$ indicated small to moderate correlations between the physiologic factors with absolute values of $r$ ranging from .05 to .521 . Additional testing for multicollinearity demonstrated a variance inflation factor $(\mathrm{VIF})<2$ and tolerance $>.3$ for all parameters. Subsequently, a between subjects multivariate analysis of variance (MANOVA) was conducted to evaluate the physiologic parameters of heart rate (HR), systolic blood pressure (SBP), respiratory rate (RR), and temperature $(T)$ in patients with and without PSH. Parameters included were the daily minimum value, daily maximum value, and frequency that the parameter was recorded outside of the pre-established normative range during the 24-hour collection period. Day one data was initially collected but not analyzed for two reasons. First, the literature clearly states that PSH is not present at the time of injury (day 1), and secondly, the protocol did not include a mechanism to control for the physiologic abnormalities associated with resuscitation and in some cases, hypovolemic shock. The results from days 7 , 14, and 20 are presented in Tables 4, 5, and 6 respectively. Day 7 reflected between group differences in maximal HR $(p<.001)$, HR frequency $(p=.004)$ and maximal $R R(p=.008)$. Post hoc testing demonstrated marginal effect sizes 
with Odds Ratio (OR) of 1 and confidence intervals $(\mathrm{Cl})$ centered at 1 for all three parameters, suggesting that all though there was statistical significance between groups the difference had no bearing on the overall outcomes of LOS or discharge disposition. Day 14 analysis yielded only significant findings of maximal HR $(p<.001$, OR 1.006, Cl 1.022-1.010) and maximal $R R(p=.038, O R$ $1.027, \mathrm{Cl} 1.017-1.038)$. By day 20 , no significant differences in any parameters were noted between groups.

The final aim of this research was to determine which previously identified factors significant predicted ICULOS. To address this aim, ICULOS was regressed on the factors $\mathrm{HR}$ maximum day $7, \mathrm{HR}$ frequency day $7, \mathrm{HR}$ maximum day 14 , RR maximum day 7 , and $H R$ frequency on day of discharge, in a hierarchical fashion. Factors were entered into the regression equation based on the degree of statistical significance from the previous MANOVA. ISS and age were also significant on initial analysis and were subsequently added to the final models. Maximum HR day 7 was entered in the first block, yielding an insignificant result. Maximum HR day 14 was added next, explaining $5.6 \%$ of the variability in ICULOS $\left(R^{2}=.056, F_{1,174}=10.247, p=0.002\right)$. $H R$ frequency at day 7 was then added without noticeable contribution. Maximum RR at day 7 was then added producing $R^{2}=.124$ with $R^{2}$ change of $.068\left(F_{1,172}=13.366, p<\right.$ .001). HR frequency at discharge, RR minimum at discharge, age, and ISS were subsequently added in additional blocks without appreciable explanation of variability or statistical significance. Although model 4, which incorporated HR maximum for days 7 and 14, HR frequency at day 7 and RR maximum at day 7 
accounted for only $12.4 \%$ of the variability in ICULOS, it was believed to be most reliable predictor of ICULOS.

\section{Discharge Characteristics}

All patients had day of discharge comparisons although the length of stay varied considerably (range 14-143 days). Both ICU and hospital lengths of stay were similar between groups ( $p=.245$ and $p=.1$ respectively). Median ICULOS was 18.1 days (SD 10.6 days) in the TBI group and 19.1 days (SD 9.84 days) for the PSH group while hospital length of stay (HOSPLOS) was 28.4 days (SD 19.3 days) in the TBI group and 30.2 days (SD 15 days) in the PSH group (Table 7).

Discharge GCS was significantly lower in the PSH group ( $p=.002)$. Mean GCS in the PSH group was 10.8 (SD 2.55) compared to the TBI group mean of 12.1 (SD 2.93).

When evaluating discharge dispositions, an ANOVA was used with the following discharge disposition groups:

1. Home or assisted living

2. Acute rehabilitation

3. Sub-acute rehabilitation, coma emergence programs or skilled nursing facility

4. Other or not specified disposition (includes long-term acute care, other acute care hospitals).

The $F$ test was statistically significant $(p=.009)$ suggesting that patients with PSH were less likely to be discharged to home (2.2\%) compared $8.6 \%$ in the TBI 
group, or acute rehabilitation settings (42.2\% PSH group versus $69.9 \%$ TBI group).

Post hoc testing showed a small to moderate effect between the groups with home versus acute rehabilitation (Odds Ratio (OR) 1.473 and 95\% confidence interval (Cl) $0.155-13.99)$, sub-acute rehabilitation versus acute rehabilitation (OR $0.112,95 \% \mathrm{Cl} 0.036-0.353)$ and other versus acute rehabilitation (OR $0.160,95 \% \mathrm{Cl} 0.022-1.143)$. Essentially, patients with an expected TBI course were 1.5 times more likely to be discharged to high level neuro-rehabilitation than those with PSH and were substantially less likely to require long-term skilled nursing or sub-acute rehabilitation.

\section{Discussion}

Findings from this study and others, suggest that despite appropriate TBI treatment, up to one third of the severe TBI population will develop $\mathrm{PSH}$; a complication that increases hospital length of stay, morbidity, and long-term disability (Hendricks, Heeren, \& Vos, 2010; Hinson \& Sheth, 2012; Lv et al., 2010; \& Perkes et al., 2010). Data from this study suggests that multiple episodes of tachycardia, present on post-injury days 7 and 14, are associated with the development of PSH. Other factors, including temperature, blood pressure, and respiratory rate appear to be less indicative of PSH.

Upon discharge from acute care, disposition varies mostly based on the patients level of arousal, although social factors or health system factors may also influence discharge disposition. For example, Argentina lacks formal neurorehabilitation programs; therefore, over $60 \%$ of patients with TBI are discharged 
to homecare (Rondina et al., 2005). Acute rehabilitation typically requires that patients actively participate in three or more hours of therapy a day and is the preferred discharge locale for patients with significant TBI. In the Unites States, over fifty percent of patients with severe TBI are discharged to rehabilitation (Bauer, McGwin, Melton, George, \& Markert, 2011; Livingston, Tripp, Biggs, \& Lavery, 2009). Transfer to sub-acute rehabilitation or skilled nursing facilities is largely associated with lower Glasgow Coma Score or other socioeconomic factors, specifically, government funded healthcare (Chan et al., 2001; Cuthbert et al., 2011; Hoffman et al., 2012). Bauer et al., (2011) reported that $25 \%$ of his sample were discharged to sub-acute rehabilitation with only $13 \%$ discharged to home. Others report rehabilitation rates as high as $89 \%$, although there was no distinction between acute and sub-acute rehabilitation (Mcllvoy, 2001; Vitaz et al., 2001). A cost benefit analysis suggests that aggressive care of the TBI patient, including acute rehabilitation is "significantly less costly than routine care" over time (Whitmore et al., 2012).

While this study indicates that PSH has no effect on short-term outcomes, such as ICULOS or HOSPLOS, the findings suggest that patients with PSH are less likely to qualify for acute rehabilitation upon hospital discharge. Because patients with PSH are discharged with lower levels of neurologic function, it can be inferred that patients with PSH have prolonged resource needs at increased costs and are less likely to receive specialty neurotrauma rehabilitation, which may further delay recovery and community re-entry. It remains unclear what factors are related to delayed responsiveness (lower GCS) in patients with PSH 
and if any treatment modalities to improve early wakefulness (higher GCS) might lead to earlier brain injury rehabilitation.

Contrary to expected findings, there were minimal differences in virtually all physiologic parameters. While this may be related to early treatment of $\mathrm{PSH}$, it may also be affected by the small sample size. Given the hemodynamic similarities between groups, it is not surprising that that no difference in ICULOS was identified. Except for free water requirements, no other differences in physiologic parameters were identified on the day of discharge. It was anticipated that parameters on day of discharge would be non-significant as a labile hemodynamic status is a contraindication for discharge.

\section{Limitations}

This study has several limitations. The sampling bias associated with use of a convenience sample limits the generalizability of these findings to other populations. Future studies would benefit from multi-center sampling.

The retrospective nature of the study limited the usefulness of the recently standardized definition of $\mathrm{PSH}$ that requires patients to exhibit five or more of the following symptoms without provocation: hyperthermia, dystonia, tachypnea, diaphoresis, hypertension, and tachycardia. Patients were included in the PSH group if they carried a diagnosis of PSH or had only 3 or more associated symptoms occurring 3 or more times in a 24 hour period since it was not possible to readily identify symptoms such as dystonia or diaphoresis from the existing documentation. Therefore, patients may have been included in the PSH group without meeting all diagnostic criteria. 
Retrospective studies are traditionally at high risk for missing data. In an effort to mitigate this, variables were collected across a 24-hour period instead of specified hours, thus ensuring capture of minimum and maximum values for each physiologic parameter. Facility policy dictates hourly vital signs with the exception of temperatures (monitored every 4 hours) in acute trauma patients; as a result, temperatures were the only variable with missing data. This condition was isolated to patients who were admitted after $8 \mathrm{pm}$.

The scope of this study did not allow for evaluation of treatment effects on PSH. While it appears that patients with PSH exhibit slower awakening than their counterparts as evidenced by the lower discharge GCS, it is not clear if this is related directly to the development of PSH or other dynamic elements. Other factors that may contribute to ongoing poor neurologic function include cortical and subcortical pathologies, delayed initiation of neuro-stimulants because of adrenergic hyperactivity, hormonal imbalances or other unidentified conditions.

Finally, during the years of interest, the principal investigator was actively engaged in the critical care management of patients with severe TBI and pursuing research interests in $\mathrm{PSH}$. As a result, patients with $\mathrm{PSH}$ were diagnosed within the first two weeks of injury and symptoms were treated accordingly. The lack of statistical significance between groups may be a reflection of the aggressive identification and treatment of $\mathrm{PSH}$ in the affected group.

\section{Conclusion}


Despite the study's limitations, findings indicate it is reasonable to utilize routine screening mechanisms for PSH in high-risk patients with severe TBI, particularly younger patients with early evidence of unprovoked tachycardia. Lower discharge GCS and discharge to facilities other than acute rehabilitation, suggest that patients with PSH have a delayed recovery. Additional studies are needed to determine if coma stimulation-type interventions improve the wakefulness of patients with PSH, therefore allowing earlier attempts at neurorehabilitation. Additional studies evaluating the efficacy of different treatment modalities are necessary in order to establish an evidence-based treatment algorithm for PSH. Lastly, future projects should focus on determining if differences in long-term recovery and functional status exist or if the natural history of PSH stabilizes, allowing equalization of outcomes in the long-term. 
Table 2

Explanation of Included and Excluded TBI Cases

\begin{tabular}{lll}
\hline Total Cases With Admit & Reason & $\mathbf{N}=\mathbf{6 2 0}$ \\
GCS 8 8 From Registry & Included/Excluded & \\
$\mathbf{2 0 1 0 - 2 0 1 5}$ & & $\mathrm{N}=424$ \\
\hline Excluded & Death & $\mathrm{N}=113$ \\
& Mild TBI (GCS 13-15) & $\mathrm{N}=69$ \\
& Moderate TBI (GCS 9- & $\mathrm{N}=203$ \\
& 12) & $\mathrm{N}=39$ \\
& No TBI (anoxia, stroke) & $\mathrm{N}=2$ \\
& Age<16 & $\mathrm{N}=1$ \\
\hline Included & Transfer within 1 week & $\mathrm{N}=196$ \\
\hline & Post-resuscitation GCS & \\
\hline & $4-8$ & \\
\hline
\end{tabular}

GCS- Glasgow Coma Score

TBI- Traumatic brain injury 
Table 3

Admission Characteristics of Patients with Severe Traumatic Brain Injury

Admitted to a Level 1 Trauma Center Between 2010-2015 (N=196).

\begin{tabular}{llll}
\hline Variable & TBI (n=151) & PSH (n=45) & Significance \\
\hline AGE Mean (SD) & $37.9(15.9)$ & $27.7(10.7)$ & $\mathrm{p}<.001^{*}$ \\
Median & 38 & 24 & \\
GCS Mean (SD) & $6.38(1.16)$ & $6.29(1.16)$ & $\mathrm{p}=0.143$ \\
Median & 7 & 6 & \\
& & & \\
ISS Mean (SD) & $29.2(10)$ & $32.9(8.63)$ & $\mathrm{p}=0.01^{*}$ \\
Median & 29 & 33.5 & \\
& & & \\
AIS Head & & 4 & \\
3 & 27 & & \\
4 & 57 & & \\
5 & 67 & & \\
AIS-Head= Abbreviated Injury Severity-Head $(1 \& 2$ excluded as minor, 6 as \\
fatal)
\end{tabular}


Table 4

Hospital Characteristics of Patients with Severe TBI on Day 7 ( $N=196)$

\begin{tabular}{llll}
\hline Variable & TBI Group & PSH Group & Significance \\
& $(\mathbf{N}=151)$ & $(\mathbf{N}=45)$ & \\
\hline HR beats per min & & & \\
Min Mean (SD) & $74.1(14.8)$ & $74.6(14.4)$ & $\mathrm{p}=0.774$ \\
Max Mean (SD) & $107(17.6)$ & $118(18.5)$ & $\mathrm{p}=<0.001^{*}$ \\
Frequency (SD) & $1.26(3.73)$ & $1.47(2.94)$ & $\mathrm{p}=0.003^{*}$ \\
SBP mm Hg & & & \\
Min (SD) & $113(13.4)$ & $110(14.6)$ & $\mathrm{p}=0.148$ \\
Max (SD) & $159(17.4)$ & $160(16.1)$ & $\mathrm{p}=0.797$ \\
Frequency (SD) & $7.21(6.35)$ & $6.93(2.94)$ & $\mathrm{p}=0.807$ \\
Temp degrees F & & & $\mathrm{p}$ \\
Min (SD) & $98.7(0.97)$ & $98.8(0.97)$ & $\mathrm{p}=0.922$ \\
Max (SD) & $101(1.2)$ & $101(1.2)$ & $\mathrm{p}=0.375$ \\
Frequency (SD) & $2.85(3.08)$ & $3.92(3.08)$ & $\mathrm{p}=0.341$ \\
RR breath/minute & & $10.7(8.51)$ & $\mathrm{p}=0.077$ \\
Min (SD) & $15.9(4.67)$ & $28.7(7.17)$ & \\
Max (SD) & $25.7(5.93)$ & & \\
Frequency (SD) & $8.35(8.01)$ & & \\
\hline
\end{tabular}

TBI- Traumatic brain injury

PSH- Paroxysmal sympathetic hyperactivity 
HR- Heart rate in beats per minute

SBP-Systolic blood pressure

Temp- Temperature in degrees Fahrenheit

RR- Respiratory rate in breaths per minute

SD- standard deviation

Min-Minimum value

Max-Maximum value

Frequency- Number of times above pre-defined normal value 
Table 5

Characteristics of Patients with Severe Traumatic brain Injury on Hospital Day 14 $(N=181)$

\begin{tabular}{|c|c|c|c|}
\hline Variable & $\begin{array}{c}\text { TBI Group } \\
(n=137)\end{array}$ & $\begin{array}{l}\text { PSH Group } \\
(n=44)\end{array}$ & Significance \\
\hline \multicolumn{4}{|l|}{ HR-beats per min } \\
\hline $\operatorname{Min}(S D)$ & $80.7(15.9)$ & $83.7(16.0)$ & $p=0.295$ \\
\hline $\operatorname{Max}(\mathrm{SD})$ & $111(18.7)$ & $122(14.8)$ & $p<0.001$ \\
\hline Frequency (SD) & $1.33(3.84)$ & $2.32(4.00)$ & $p=0.054$ \\
\hline \multicolumn{4}{|l|}{ SBP mm HG } \\
\hline $\operatorname{Min}(S D)$ & $110(13.9)$ & $109(13.2)$ & $p=0.276$ \\
\hline $\operatorname{Max}(S D)$ & $148(18.3)$ & $152(17.7)$ & $p=0.130$ \\
\hline Frequency (SD) & $3.82(5.42)$ & $4.52(5.54)$ & $p=0.238$ \\
\hline \multicolumn{4}{|l|}{ Temp in $\mathrm{F}$} \\
\hline Min (SD) & $98.2(1.20)$ & $98.4(0.666)$ & $p=0.602$ \\
\hline $\operatorname{Max}(S D)$ & $99.3(7.99)$ & $100(1.11)$ & $p=0.289$ \\
\hline Frequency (SD) & $1.35(2.60)$ & $1.39(2.31)$ & $p=0.597$ \\
\hline \multicolumn{4}{|l|}{ RR breath/minute } \\
\hline $\operatorname{Min}(S D)$ & $17.5(3.95)$ & $17.2(3.87)$ & $p=0.975$ \\
\hline $\operatorname{Max}(S D)$ & $26.8(6.70)$ & $28.3(6.67)$ & $p=0.147$ \\
\hline Freq (SD) & $8.33(8.20)$ & $10.1(8.56)$ & $p=0.279$ \\
\hline \multicolumn{4}{|l|}{ Free Water $(\mathrm{mL})$} \\
\hline Mean (SD) & $192(351)$ & $229(436)$ & $P=0.850$ \\
\hline
\end{tabular}


SD- Standard deviation

TBI- Traumatic brain injury

PSH- Paroxysmal sympathetic hyperactivity

Temp- Temperature

Min- Minimum value

Max- Maximum value

Frequency- Number of times above predefined normal value 
Table 6

Characteristics of Patients with Severe Traumatic Brain Injury on Hospital Day 20 $(N=137)$

\begin{tabular}{|c|c|c|c|}
\hline Variable & $\begin{array}{l}\text { TBI Group } \\
(n=101)\end{array}$ & $\begin{array}{l}\text { PSH Group } \\
(n=36)\end{array}$ & Significance \\
\hline \multicolumn{4}{|l|}{ HR beats /min } \\
\hline $\operatorname{Min}(S D)$ & $82.7(15.4)$ & $81.8(14.4)$ & $p=0.940$ \\
\hline $\operatorname{Max}(S D)$ & $108(17.4)$ & $114(17.3)$ & $p=0.074$ \\
\hline Frequency (SD) & $0.95(2.87)$ & $1.39(2.77)$ & $p=0.126$ \\
\hline \multicolumn{4}{|l|}{ SBP mm Hg } \\
\hline Min (SD) & $111(14.1)$ & $105(12.0)$ & $p=0.053$ \\
\hline $\operatorname{Max}(S D)$ & $141(18.1)$ & $144(18.0)$ & $p=0.468$ \\
\hline Frequency (SD) & $1.86(3.53)$ & $1.97(3.97)$ & $p=0.715$ \\
\hline \multicolumn{4}{|l|}{ Temp deg $\mathrm{F}$} \\
\hline $\operatorname{Min}(S D)$ & $97.8(0.92)$ & $98.0(0.76)$ & $p=0.177$ \\
\hline $\operatorname{Max}(S D)$ & $100(10.2)$ & $99.6(1.13)$ & $p=0.373$ \\
\hline Frequency (SD) & $0.69(2.15)$ & $0.42(0.77)$ & $p=0.7337$ \\
\hline \multicolumn{4}{|l|}{$\mathrm{RR}$ breaths/min } \\
\hline $\operatorname{Min}(S D)$ & $17.2(3.61)$ & $16.1(3.10)$ & $p=0.059$ \\
\hline $\operatorname{Max}(\mathrm{SD})$ & $23.4(5.63)$ & $24.7(7.60)$ & $p=0.771$ \\
\hline Frequency (SD) & $4.44(7.10)$ & $5.64(7.82)$ & $p=0.613$ \\
\hline Free Water $(\mathrm{mL})$ & $296(463)$ & 391 (573) & $p=0.434$ \\
\hline
\end{tabular}


TBI- Traumatic brain injury

PSH- Paroxysmal sympathetic hyperactivity

$\mathrm{HR}$ beat/min- Heart rate in beats per minute

SBP-Systolic blood pressure

Temp deg F- Temperature in degrees Fahrenheit

RR- Respiratory rate in breaths per minute

SD- Standard deviation

Frequency- Number of times above predetermined normal value 


\section{Table 7}

Discharge Characteristics of Patients with Expected TBI Recovery and Those with PSH (N=196).

\begin{tabular}{llll}
\hline Variable & TBI $(\mathbf{n}=\mathbf{1 5 1})$ & PSH $(\mathbf{n}=\mathbf{4 5})$ & Significance \\
\hline Discharge GCS & & & \\
Mean(SD) & $12.1(2.55)$ & $10.8(2.93)$ & $\mathrm{p}=0.002$ \\
Median & 14.0 & 10.5 & \\
ICULOS & & & \\
Mean (SD) day & $18.1(10.6)$ & $19.1(9.84)$ & $\mathrm{p}=0.245$ \\
Median day & 16.0 & 17.0 & \\
Range in days & $5-83$ & $7-65$ & \\
HOSPLOS & & & \\
Mean (SD) day & $28.4(19.3)$ & $30.2(15)$ & $\mathrm{p}=0.100$ \\
Median day & 23.0 & 24.0 & \\
Discharge Dispo & & & \\
Acute \% & 60.9 & 42.2 & \\
Home/AL \% & 8.6 & 2.2 & \\
SAR/SNF/Emerge \% & 23.8 & 48.9 & \\
Other \% & 6.6 & 6.7 & \\
\hline
\end{tabular}

TBI- Traumatic brain injury

PSH- Paroxysmal sympathetic hyperactivity

GCS- Glasgow Coma Score 
ICULOS- Intensive Care Unit length of stay

HOSPLOS- Hospital Length of Stay

Discharge Dispo- Discharge disposition

Acute-Acute rehabilitation

AL-Assisted living

SAR- Subacute rehabilitation

SNF- Skilled nursing facility

Emerge- Coma emergence program 
Figure 3

Mechanism of injury for traumatic brain injury, years $2010-2015$ TBI versus PSH groups $(p=.079)$

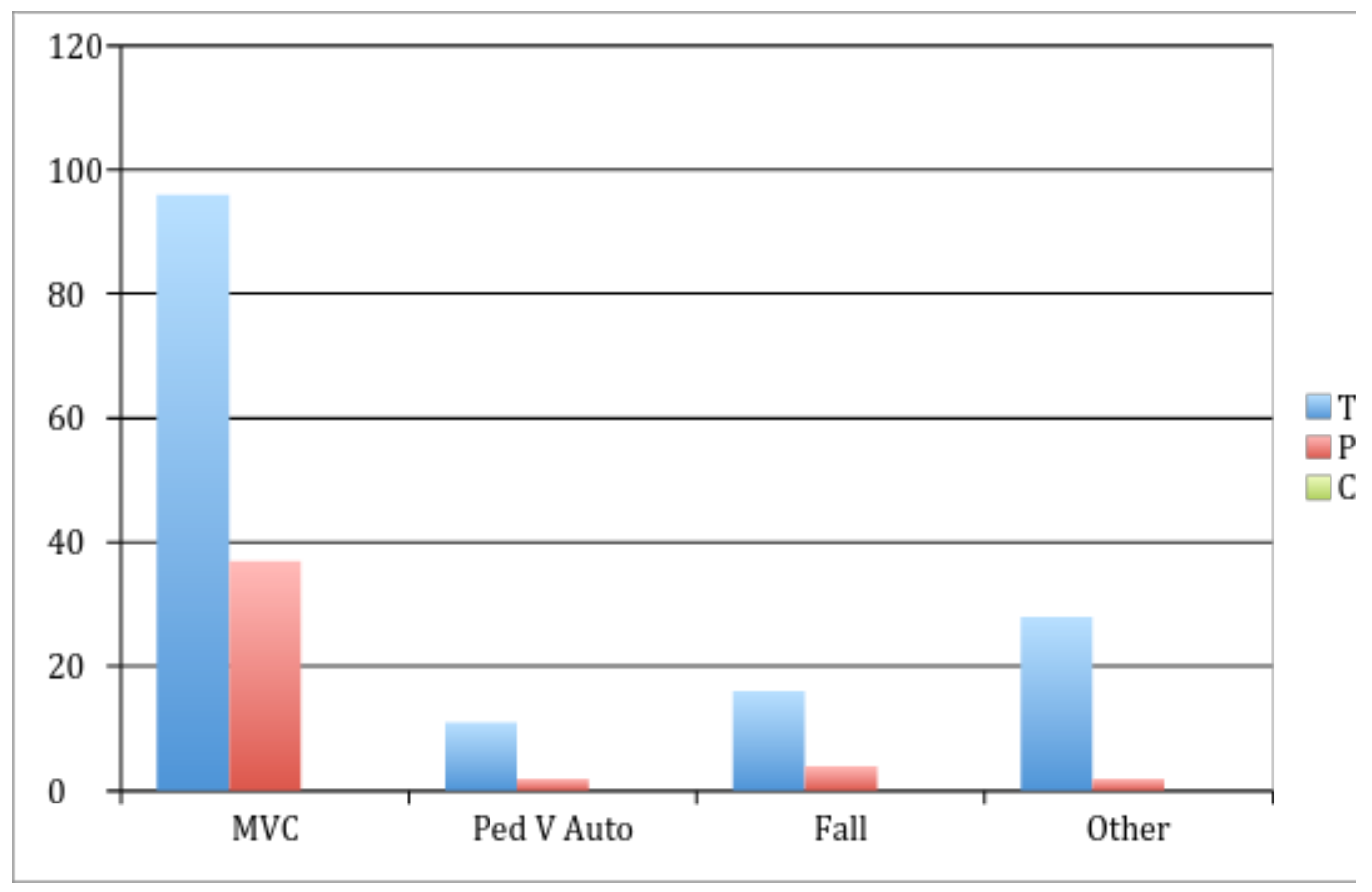

MVC includes: All-terrain vehicle, motorcycle, motor vehicle, and moped crashes

Ped $v$ Auto- includes any pedestrian struck my motorized vehicle

Other includes: Plane accident, bicycle accident, found down, assault, and gunshot wound. 


\section{CHAPTER V \\ SUMMMARY AND CONCLUSIONS}

Paroxysmal sympathetic hyperactivity is a complication that follows TBI in a small percent of patients in a coma (Fernandez-Ortega et al., 2012). Although cases of PSH were identified over 60 years ago, formal diagnostic criteria and nomenclature have only been established within the last five years (Baguley et al., 2014). To date, most of the research in this area has emerged from a single group in Australia. Their findings indicate that patients who develop PSH are at risk for increased morbidity, prolonged ICULOS, and delayed recovery (Fernandez-Ortega et al., 2012; Baguley, 2008a; Penfield, 1929; Baguley et al., 2006; Baguley et al., 1999).

Consistent with prior research, this study suggests that younger patients with severe TBI are most at risk for developing PSH. The presence of diffuse axonal injury on imaging studies has been associated with PSH (Hinson \& Sheth, 2012; Lv et al., 2011). However, other clinically relevant injury related factors (AIS-head, ICP, admission GCS) do not have an obvious linkage to the development of PSH. 
Early and persistent episodes of non-specific tachycardia appear to be the most sensitive indicator for $\mathrm{PSH}$ although other factors such as early tachypnea and late pyrexia after TBI may also indicate the presence of PSH. As most of the patients in this study were diagnosed with PSH early in their hospital course and had ICULOS similar to their TBI counterparts, it is possible that early PSH intervention may prevent prolonged ICULOS and thereby associated complications. Comparative studies looking the effects of early versus delayed treatment of PSH may offer insight into the differences in outcomes from various studies.

Despite similar admission characteristics, ICULOS, and HOSPLOS, patients with $\mathrm{PSH}$ appear to have slower awakening from coma as evidenced by lower discharge GCS. Poor neurologic function at discharge likely influences discharge disposition. Patients with PSH are less likely to be discharged to acute neurorehabilitation than their TBI counterparts who follow an expected TBI recovery trajectory.

Much is left to learn about the complex condition of PSH. Future research priorities should include:

- Creation and validation of a PSH screening tool

- Development of evidence-based treatment protocols

- Establishment of the natural history of PSH

- Determine the long-term functional outcomes of patients with PSH 
Due to the low incidence of PSH, sample size limitations pose a significant problem in powering single site studies. For this reason, multi-center studies should be considered. 


\section{REFERENCES}

Anonymous. (2012). What causes thunderstorms? Retrieved from http://www.weatherquestions.com/What_causes_thunderstorms.htm

Baguley, I. J. (2008a). Autonomic complications following central nervous system injury. Seminars in Neurology, 28(5), 716-725. doi:10.1055/s-00281105971

Baguley, I. J. (2008b). The excitatory:inhibitory ratio model (EIR model): An integrative explanation of acute autonomic overactivity syndromes. Medical Hypotheses, 70(1), 26-35. doi:10.1016/j.mehy.2007.04.037

Baguley, I. J. (2013). Paroxysmal Sympathetic Hyperactivity Following acquired brain injury: a coming of age. Retrieved from http://www.internationalbrain.org/articles/paroxysmal-sympathetichyperactivity-after-acquired-brain-injury/

Baguley, I. J., Cameron, I. D., Green, A. M., Slewa-Younan, S., Marosszeky, J. E., \& Gurka, J. A. (2004). Pharmacological management of dysautonomia following traumatic brain injury. Brain Injury, 18(5), 409-417. doi:10.1080/02699050310001645775

Baguley, I. J., Heriseanu, R. E., Cameron, I. D., Nott, M. T., \& Slewa-Younan, S. (2008). A critical review of the pathophysiology of dysautonomia following traumatic brain injury. Neurocritical Care, 8(2), 293-300. doi:10.1007/s12028-007-9021-3 
Baguley, I. J., Heriseanu, R. E., Felmingham, K. L., \& Cameron, I. D. (2006). Dysautonomia and heart rate variability following severe traumatic brain injury. Brain Injury, 20(4), 437-444. doi:10.1080/02699050600664715

Baguley I.J., Heriseanu, R. E., Gurka, J.A., Nordenbo, A, \& Cemeron, I. D. (2007). Gabapentin in the management of dysautonomia following severe traumatic brain injury: a case series. Journal of Neurology, Neurosurgery \& Psychiatry, 78(5), 539-541. doi:10.1136/jnnp.2006.096388

Baguley ,I.J., Heriseanu, R.E., Nott, M.T,, Chapman, J, \& Sandanam, J. (2009). Dysautonomia after severe traumatic brain injury: evidence of persisting overresponsiveness to afferent stimuli. American Journal of Physical Medicine \& Rehabilitation, 88(8), 615-622.

doi:10.1097/PHM.0b013e3181aeab96

Baguley, I., Nicholls, J., Felmingham, K., Crooks, J., Gurka, J., \& Wade, L. (1999). Dysautonomia after traumatic brain injury: a forgotten syndrome? Journal of Neurology, Neurosurgery \& Psychiatry, 67(1), 39-43.

Baguley, I.J., Nott, M.T., Slewa-Younan, S, Heriseanu, R., \& Perkes, I. (2009). Diagnosing dysautonomia after acute traumatic brain injury: evidence for overresponsiveness to afferent stimuli. Archives of Physical Medicine \& Rehabilitation, 90(4), 580-586. doi:10.1016/j.apmr.2008.10.020

Baguley, I. J., Perkes, I. E., Fernandez-Ortega, J. F., Rabinstein, A. A., Dolce, G., Hendricks, H. T., \& Consensus Working, G. (2014). Paroxysmal sympathetic hyperactivity after acquired brain injury: consensus on 
conceptual definition, nomenclature, and diagnostic criteria. Journal of Neurotrauma, 31(17), 1515-1520. doi:10.1089/neu.2013.3301

Baguley, I. J., Slewa-Younan, S., Heriseanu, R. E., Nott, M. T., Mudaliar, Y., \& Nayyar, V. (2007). The incidence of dysautonomia and its relationship with autonomic arousal following traumatic brain injury. Brain Injury, 21(11), 1175-1181. doi:10.1080/02699050701687375

Bauer, D. F., McGwin, G., Jr., Melton, S. M., George, R. L., \& Markert, J. M. (2011). Risk factors for conversion to permanent ventricular shunt in patients receiving therapeutic ventriculostomy for traumatic brain injury. Neurosurgery, 68(1), 85-88. doi:10.1227/NEU.0b013e3181fd85f4

Becker, R., Benes, L., Sure, U., Hellwig, D., \& Bertalanffy, H. (2000). Intrathecal baclofen alleviates autonomic dysfunction in severe brain injury. Journal of Clinical Neurosciences, 7(4), 316-319. doi:10.1054/jocn.1999.0227

Boeve, B. F., Wijdicks, E. F., Benarroch, E. E., \& Schmidt, K. D. (1998a). Paroxysmal sympathetic storms ("diencephalic seizures") after severe diffuse axonal head injury. Mayo Clinic Proceedings, 73(2), 148-152. doi:10.1016/S0025-6196(11)63647-1

Bower, R. S., Sunnarborg, R., Rabinstein, A. A., \&Wijdicks, E. F. (2010). Paroxysmal sympathetic hyperactivity after traumatic brain injury. Neurocritical Care, 13(2), 233-234. doi:10.1007/s12028-010-9381-y Bruns, J., Jr., \& Hauser, W. A. (2003). The epidemiology of traumatic brain injury: a review. Epilepsia, 44 (Suppl 10): 2-10. 
Bullard, D. E. (1987).Diencephalic seizures: responsiveness to bromocriptine and morphine. Annals of Neurology, 21(6), 609-611.

Centers for Disease Control and Prevention. (2010). Injury Prevention \& Control:

Traumatic Brain Injury. Retrieved from

http://www.cdc.gov/TraumaticBrainlnjury/index.html

Chan, L., Doctor, J., Temkin, N., MacLehose, R. F., Esselman, P., Bell, K., \&

Dikmen, S. (2001). Discharge disposition from acute care after traumatic brain injury: the effect of insurance type. Archives of Physical Medicine \& Rehabilitation, 82(9), 1151-1154. doi:10.1053/apmr.2001.24892

Corrigan, J. D., Selassie, A. W., \& Orman, J. A. (2010). The epidemiology of traumatic brain injury. Journal of Head Trauma Rehabilitation, 25(2), 7280. doi:10.1097/HTR.0b013e3181ccc8b4

Cuny, E., Richer, E., \& Castel, J. P. (2001). Dysautonomia syndrome in the acute recovery phase after traumatic brain injury: relief with intrathecal Baclofen therapy. Brain Injury, 15(10), 917-925. doi:10.1080/02699050110065277 Cuthbert, J. P., Corrigan, J. D., Harrison-Felix, C., Coronado, V., Dijkers, M. P., Heinemann, A. W., \& Whiteneck, G. G. (2011). Factors that predict acute hospitalization discharge disposition for adults with moderate to severe traumatic brain injury. Archives of Physical Medicine\& Rehabilitation, 92(5), 721-730 e723. doi:10.1016/j.apmr.2010.12.023

Fernandez-Ortega, J. F., Prieto-Palomino, M. A., Garcia-Caballero, M., GaleasLopez, J. L., Quesada-Garcia, G., \& Baguley, I. J. (2012). Paroxysmal sympathetic hyperactivity after traumatic brain injury: clinical and 
prognostic implications. Journal of Neurotrauma, 29(7), 1364-1370. doi:10.1089/neu.2011.2033

Fernandez-Ortega, J. F., Prieto-Palomino, M. A., Munoz-Lopez, A., LebronGallardo, M., Cabrera-Ortiz, H., \& Quesada-Garcia, G. (2006). Prognostic influence and computed tomography findings in dysautonomic crises after traumatic brain injury. Journal of Trauma, 61(5), 1129-1133. doi:10.1097/01.ta.0000197634.83217.80

Frankel, J. E., Marwitz, J. H., Cifu, D. X., Kreutzer, J. S., Englander, J., \& Rosenthal, M. (2006). A follow-up study of older adults with traumatic brain injury: taking into account decreasing length of stay. Archives of Physical Medicine \& Rehabilitation, 87(1), 57-62.

doi:10.1016/j.apmr.2005.07.309

Gao, B., Pollock, J. A., \& Hinson, H. E. (2014). Paroxysmal sympathetic hyperactivity in hemispheric intraparenchymal hemorrhage. Annals of Clinical of Translation Neurology, 1(3), 215-219. doi:10.1002/acn3.44

Haas, B., Jurkovich, G. J., Wang, J., Rivara, F. P., Mackenzie, E. J., \& Nathens, A. B. (2009). Survival advantage in trauma centers: expeditious intervention or experience? Journal of American College of Surgery, 208(1), 28-36. doi:10.1016/j.jamcollsurg.2008.09.004

Hendricks, H. T., Heeren, A. H., \& Vos, P. E. (2010). Dysautonomia after severe traumatic brain injury. European Journal of Neurology, 17(9), 1172-1177. doi:10.1111/j.1468-1331.2010.02989.x 
Hinson, H. E., \& Sheth, K. (2012). Manifestations of the hyperadrenergic state after acquired brain injury. Current Opinion in Critical Care, 18(2), 139145. doi:10.1097/MCC.0b013e3283513290

Hoffman, J. M., Donoso Brown, E., Chan, L., Dikmen, S., Temkin, N., \& Bell, K. R. (2012). Change in inpatient rehabilitation admissions for individuals with traumatic brain injury after implementation of the Medicare inpatient rehabilitation facility prospective payment system. Archives of Physical Medicine \& Rehabilitation, 93(8), 1305-1312.

doi:10.1016/j.apmr.2012.04.030

Hutchinson, S. A., \& Wilson, H. S. (1998). The Theory of Unpleasant Symptoms and Alzheimer's disease. Scholarly Inquiry for Nursing Practice, 12(2), 143-158; discussion 159-162.

Kauh, B., Polak, T., Hazelett, S., Hua, K., \& Allen, K. (2005). A pilot study: postacute geriatric rehabilitation versus usual care in skilled nursing facilities. Journal of the American Medical Directors Association, 6(5), 321-326. doi:10.1016/j.jamda.2005.04.008

Kelly D. \& Vincent L. (2010). The dimensions of nursing surveillance: a concept analysis. Journal of Advanced Nursing, 67(3), 652-661. doi:10.1111/j.1365-2648.2010.05525.x.

Kramer, A. H., \& Zygun, D. A. (2014). Neurocritical care: why does it make a difference? Current Opinions in Critical Care, 20(2), 174-181. doi:10.1097/MCC.0000000000000076. 
Lemke, D. (2003). Riding out the storm: sympathetic storming after traumatic brain injury. Journal of Neuroscience Nursing, 36, 4-9.

Lemke, D. (2007). Sympathetic storming after severe traumatic brain injury. Critical Care Nurse, 27(1), 30-37.

Lenz, E. R., Pugh, L. C., Milligan, R. A., Gift, A., \& Suppe, F. (1997). The middlerange theory of unpleasant symptoms: an update. Advances in Nursing Science, 19(3), 14-27.

Lenz, E. R., Suppe, F., Gift, A. G., Pugh, L. C., \& Milligan, R. A. (1995). Collaborative development of middle-range nursing theories: toward a theory of unpleasant symptoms. Advances in Nursing Science, 17(3), 113.

Lv, L.-Q., Hou, L.-J., Yu, M.-K., Qi, X.-Q., Chen, H.-R., Chen, J.-X., . . Lu, Y.-C. (2011). Risk factors related to dysautonomia after severe traumatic brain injury. Journal of Trauma, 71(3), 538-542.

Lv, L. Q., Hou, L. J., Yu, M. K., Ding, X. H., Qi, X. Q., \& Lu, Y. C. (2011). Hyperbaric oxygen therapy in the management of paroxysmal sympathetic hyperactivity after severe traumatic brain injury: a report of 6 cases. Archives of Physical Medicine \& Rehabilitation, 92(9), 1515-1518. doi:10.1016/j.apmr.2011.01.014.

Lv, L. Q., Hou, L. J., Yu, M. K., Qi, X. Q., Chen, H. R., Chen, J. X., . . Lu, Y. C. (2010). Prognostic influence and magnetic resonance imaging findings in paroxysmal sympathetic hyperactivity after severe traumatic brain injury. Journal Neurotrauma, 27(11), 1945-1950. doi:10.1089/neu.2010.1391 
Mcllvoy, L. H. (2005). The effect of hypothermia and hyperthermia on acute brain injury. AACN Clinical Issues, 16(4), 488-500.

Meyer, K. S. (2014). Understanding paroxysmal sympathetic hyperactivity after traumatic brain injury. Surgical Neurology International, 5(Suppl 13), S490-492. doi:10.4103/2152-7806.144632.

Motl, R. W., \& McAuley, E. (2009). Symptom cluster as a predictor of physical activity in multiple sclerosis: preliminary evidence. Journal of Pain \& Symptom Management, 38(2), 270-280. doi:10.1016/j.jpainsymman.2008.08.004.

Onushko, T., Hyngstrom, A., \& Schmit, B. D. (2010). Effects of multijoint spastic reflexes of the legs during assisted bilateral hip oscillations in human spinal cord injury. Archives of Physical Medicine\& Rehabilitation, 91(8), 1225-1235. doi:10.1016/j.apmr.2010.04.014.

Patel, M. B., McKenna, J. W., Alvarez, J. M., Sugiura, A., Jenkins, J. M., Guillamondegui, O. D., \&Pandharipande, P. P. (2012). Decreasing adrenergic or sympathetic hyperactivity after severe traumatic brain injury using propranolol and clonidine (DASH After TBI Study): study protocol for a randomized controlled trial. Trials, 13, 177. doi:10.1186/1745-6215-13177.

Payen, D., Quintin, L., Plaisance, P., Chiron, B., \&Lhoste, F. (1990). Head injury: clonidine decreases plasma catecholamines. Critical Care Medicine, 18(4), 392-395.

Penfield, W. (1929). Autonomic Diencephalic Epilepsy,..Canadian Medical 
Association Journal, 1929.20(5): p. 521-2.

Perkes, I., Baguley, I. J., Nott, M. T., \&Menon, D. K. (2010). A review of paroxysmal sympathetic hyperactivity after acquired brain injury. Annals of Neurology, 68(2), 126-135. doi:10.1002/ana.22066.

Petroni, G., Quaglino, M., Lujan, S., Kovalevski, L., Rondina, C., Videtta, W., . . . Chesnut, R. (2010). Early prognosis of severe traumatic brain injury in an urban Argentinian trauma center. Journal of Trauma, 68(3), 564-570. doi:10.1097/TA.0b013e3181ce1eed.

Rabinstein, A. A. (2007). Paroxysmal sympathetic hyperactivity in the neurological intensive care unit. Neurological Research, 29(7), 680-682. doi:10.1179/016164107X240071.

Rodgers, B. (2000). Concept analysis: an evolutionary view. In Rodgers, B. L. \& Knafl, K. A. (Eds.), Concept Development in Nursing (pp. 77-101). Philadelphia, PA: Saunders.

Rondina, C., Videtta, W., Petroni, G., Lujan, S., Schoon, P., Mori, L. B., . . . Chesnut, R. (2005). Journal of Head Trauma Rehabilitation, 20(4), 368376.

Rossitch, E., Jr., \& Bullard, D. E. (1988). The autonomic dysfunction syndrome: aetiology and treatment. British Journal of Neurosurgery, 2(4), 471-478.

Russo, R. N., \& O'Flaherty, S. (2000). Bromocriptine for the management of autonomic dysfunction after severe traumatic brain injury. Journal of Paediatric Child Health, 36(3), 283-285. 
Vitaz, T. W., Mcllvoy, L., Raque, G. H., Spain, D., \& Shields, C. B. (2001). Development and implementation of a clinical pathway for severe traumatic brain injury. Journal of Trauma, 51(2), 369-375.

Wheaton, P., Mathias, J. L., \& Vink, R. (2009). Impact of early pharmacological treatment on cognitive and behavioral outcome after traumatic brain injury in adults: a meta-analysis. Journal of Clinical Psychopharmacology, 29(5), 468-477. doi:10.1097/JCP.0b013e3181b66f04.

Whitmore, R. G., Thawani, J. P., Grady, M. S., Levine, J. M., Sanborn, M. R., \& Stein, S. C. (2012). Is aggressive treatment of traumatic brain injury costeffective? Journal of Neurosurgery, 116(5), 1106-1113. doi:10.3171/2012.1.JNS11962.

Whyte, J., Nordenbo, A. M., Kalmar, K., Merges, B., Bagiella, E., Chang, H., . . . Giacino, J. (2013). Medical complications during inpatient rehabilitation among patients with traumatic disorders of consciousness. Archives of Physical Medicine \& Rehabilitation, 94(10), 1877-1883. doi:10.1016/j.apmr.2012.12.027. 


\section{Appendix1}

\section{Permission from the editor regarding manuscript 1.}

Meyer,K. S. (2014)

Jim Cook <editor@surgicalneurologyint.com>

Ned 4/6, 4:16 PM

- S Reply all $\mid V$

Kimberly Meyer <kimbemey@ulh.org>; Meyer,Kimberly S z

You forwarded this message on 4/7/2016 12:45 PM

Dear Kim,

Your article was published under the terms of the Creative Commons license, so you are free to use the article (or any part of it) any way you see fit, as long as it is properly cited.

Best regards,

Jim

Jim Cook

Managing Editor

Surgical Neurology International

31855 Date Palm Drive, Suite 3-400

Cathedral City, CA 92234

U.S.A. 


\section{CURRICULUM VITAE \\ Kimberly Meyer, MSN}

\section{Personal Data}

Address: 4162 Lakeside $\mathrm{Dr}$

Sellersburg, IN 47172

Email: ksmeyer21@gmail.com or k0meye01@cardmail.louisville.edu Cell: 502.727.3896

\section{Academic Degrees}

University of Louisville

University of Kentucky

University of Louisville

University of Louisville

\section{Licensure}

Kentucky RN

Kentucky APRN

DEA
BSN

MSN

PhD Student

PhD candidate

1070614

3003581

Available upon request
1988-1992

1998-2001

2012-2015

2015- present

\section{Certifications}

American Nurses Credentialing Center

Acute Care Nurse Practitioner (ACNP) 2001-present

American Association of Neuroscience Nurses

CNRN

1997-present

American Association of Critical Care Nurses 
CCRN

$1995-2001$

American Heart Association

ACLS Instructor

1995-2001

\section{Professional Affiliations}

Congress of Neurological Surgeons 2012-present

Neurocritical Care Society

2009-present

American Association of Neuroscience Nurses

1995-present

Nominating Committee

2011-2014

American Association of Critical Care Nurses

2009-present

American Board of Neuroscience Nurses

Board of Directors

Mar2008-2010

President (ABNN)

Mar2010-Mar2011

Past-president (ABNN)

Mar2011-Mar2012

\section{Employment History}

Lecturer (Contract)

2014 - present

University of Louisville School of Nursing

Geriatric-Adult Acute Care Nurse Practitioner Track

Neurosurgery Nurse Practitioner

2010- present

University of Louisville Hospital

Neuroscience Clinician/TBI specialist $2007-2013$

Defense and Veterans Brain Injury Center

Washington DC

- Traumatic brain injury (TBI) policy development

- Subject matter expert (TBI) for Department of Defense 
- Provider training

Neurosurgery Nurse Practitioner

2001-2007

University of Louisville Dept. of Neurosurgery

Louisville, KY

- Neurocritical care/management of neurosurgery patients

- In-house neurosurgery call

- Admission/discharge of neurosurgery patients

Adjunct Faculty- Neuroscience Content

2001

Midway College

Midway, KY

Clinical Research Coordinator

1998-2001

University of Louisville, Dept of Neurosurgery

- Participated in American Brain Injury Consortium project development

- Pfizer CP101,606 Phase II study

Staff Nurse/Preceptor

1993-1998

Surgical ICU

University of Louisville Hospital

Staff Nurse/Alternate Charge Nurse

1992-1993

Trauma Step-down Unit

University of Louisville Hospital

\section{Editorial Activity}

Surgical Neurology

01/2014-present

Editorial Board- Nursing

Peer Reviewer for trauma, stroke, and oncology

Journal of Neuroscience Nursing

1999-2007 


\section{Special Recognition}

University of Louisville

2014-2015

Faculty Favorite

Best Abstract: World Federation of Neuroscience Mar 2009

Nurses "Visual \& Vestibular Complications Associated with TBI"

Certificate of Appreciation

Health \& Human Services Administration

Organ Donation Breakthrough Collaborative

Certificate of Appreciation

Brain Injury Association of Kentucky

Certificate of Appreciation

Kentucky Organ Donor Affiliates

\section{Research}

Impact of Paroxysmal Sympathetic Hyperactivity Following Traumatic Brain Injury on Length of Stay and Discharge Disposition (Doctoral Dissertation)

2015- present

- Principal Investigator

Amantadine for Traumatic Brain Injury: Impact on Recovery. A Retrospective Study 2013-2016

- Co-investigator

North American Clinical Trials Network (NACTN) for the Treatment of Spinal Cord Injury 2011- present

- Sub-investigator

ATACH-II Trial (multicenter, industry sponsored) 2011-2015 
- Antihypertensive treatment of Intracranial hemorrhage

- Co-investigator

SYNAPSE (multicenter, industry sponsored) 2012-2015

- Progesterone versus placebo for severe traumatic brain injury

- Sub-investigator

Phase III Acute severe TBI (Pfizer, CP101,606) 1998-2001

- Research Nurse

- High enrolling center

\section{National Committees/Special Projects}

Neurocritical Care Society: DVT Guideline Committee (2014-2016).

Centers for Disease Control: Concussion Definition Workgoup (2010-2016).

\section{Publications}

Meyer KS \& Marion DW. (2016). Chapter 58: Traumatic brain injury. In Vincent JL, Abraham E, Kochanek P, Moore FA, \& Fink M (eds), Textbook of Critical Care, 7th ed pp.220-230. Philadelphia, PA.Elsevier.

Meyer, KS. (2014). Understanding paroxysmal sympathetic hyperactivity after traumatic brain injury. Surgical Neurology International, 5(Suppl 13), S490.

Centers for Disease Control. (2013). Report to Congress on Traumatic Brain Injury in the United States: Understanding the Public Health Problem among Current and Former Military Personnel: Atlanta, GA: Centers for Disease Control and Prevention.

http://www.cdc.gov/traumaticbraininjury/pdf/report_to_congress_on_traumatic_br ain_injury_2013-a.pdf 
Hu, J., Ugilweneza, B., Meyer, K., Lad, S. P., \& Boakye, M. (2013). Trend and geographic analysis for traumatic brain injury mortality and cost based on Marketscan database.J Neurotrauma, 30(20): 1755-61.

Meyer K, \& Jaffee MS. (2013). Chapter 19: Military Personnel and Veterans with Traumatic Brain Injury. In Arciniegas DB, Zasler ND, Vanderploeg RD, \&J affee MS (eds), Management of adults with traumatic brain injury, pp461-474. Washington DC. APA.

Meyer KS \& Marion DW. (2011). Chapter 38: Traumatic brain injury. In Vincent JL, Abraham E, Kochanek P, Moore FA, \& Fink M (eds), Textbook of Critical Care, $6^{\text {th }}$ ed pp.220-230. Philadelphia, PA.Elsevier.

Jaffee MS, Kennedy J, Leal F, \& Meyer KS. (2011). Chapter 12: PTSD and TBI. In Silver J, McAllister T \&Yudofsky SC (eds.), Textbook of Traumatic Brain Injury, $2^{\text {nd }}$ ed, pp 199-210. Washington DC. APA

Meyer KS, Ivins B, Doncevic S, Lew HL, Trudel T, \&Jaffee MS. (2011). Chapter 26: TBI in the Context of War. In Silver J, McAllister T \&Yudofsky SC (eds.), Textbook of Traumatic Brain Injury, $2^{\text {nd }}$ ed. Pp 415-426. Washington DC. APA.

Mcllvoy, L, Meyer, K \& McQuillan. (2010). Traumatic spine injuries. In MK Bader \& LR Littlejohns (eds.), AANN Core Curriculum for Neuroscience Nursing $5^{h}$ edSt Louis, MO. Saunders.

Mcllvoy, L, Meyer, et al. (2010). Craniocerebral trauma. In MK Bader \& LR Littlejohns (eds.), AANN Core Curriculum for Neuroscience Nursing $5^{h}$ edSt Louis, MO. Saunders. 
Meyer KS, Marion DW, Coronel H, \& Jaffee MS. (2010). Combat-related traumatic brain injury and its implications in military healthcare. Psych Clinics of North America, 33(4): 783-96.

Drake Al, Meyer KS, Cessante LM, Cheung CR, Cullen MA, McDonald EC, \& Holland MC. (2010). Routine TBI screening following combat deployments. Neurorehab, 26(3): 183-9.

Jaffee MS \& Meyer KM. (2009). A brief overview of TBI \& PTSD within the Department of Defense.Clin Neuropsychologist; 23(8); 1291-8.

Jaffee MS, Helmick K, Girard P, Meyer KS, Dinegar K \& George K. (2009). Acute clinical care and care coordination of TBI within the Department of Defense. Journal of Rehabilitation, Research and Design; 46(6): 655-66.

Meyer KS, Helmick K, Doncevic S, \& Park R. (2008). Severe and penetrating traumatic brain injury in the context of war. Journal of Trauma Nursing, 14(4): 26.

Mcilvoy L \& Meyer KS. (2008). Nursing Management of adults with severe traumatic brain injury. AANN Clinical Practice Guideline Series. Thompson $\mathrm{H}$ (ed). Glenview, IL: AANN.

Mcilvoy L \& Meyer K. (2008).Cerebral edema management. In B. J. Ackley, G. B. Ladwig, B. A. Swan, \& S. J. Tucker (Eds.), Evidence-Based Nursing Care Guidelines: Medicial-Surgical Interventions (pp. 154-160). St. Louis, MO: Elsevier.

Mcilvoy L \& Meyer K. (2008). Cerebral perfusion promotion. In B. J. Ackley, G. B. Ladwig, B. A. Swan, \& S. J. Tucker (Eds.), Evidence-Based Nursing Care 
Guidelines: Medical-Surgical Interventions (pp. 160-163). St. Louis, MO:

Elsevier.

Mcllvoy, L, Meyer, K \& McQuillan. (2004). Traumatic spine injuries. In MK Bader \& LR Littlejohns (eds.), AANN Core Curriculum for Neuroscience Nursing $4^{\text {th }}$ ed (pp. 335-402). St Louis, MO. Saunders.

Christian WJ, Carroll M, Meyer K, Vitaz TW, \& Franklin GA. (2003). Motorcycle helmets and head injuries in Kentucky, 1995-2000. Journal of the Kentucky Medical Association, 101:21-26.

Mcllvoy L, Meyer KM, \& Vitaz TW. (2000). Utilization of an acute spinal cord injury pathway. Critical Care Nursing Clinics of North America 12(4):521-530.

Mcllvoy LH,, Spain DA, Raque GH, Vitaz TW, Boaz P, \& Meyer KM. (2001). Successful incorporation of the Severe Head Injury Guidelines into a phasedoutcome clinical pathway. Journal of Neuroscience Nursing, 33(2):72-8, 82.

\section{Presentations/Abstracts}

Meyer, KS. (Poster presentation). The Effects of Paroxysmal Sympathetic Hyperactivity Following Traumatic Brain Injury on Discharge Disposition. Researh!Louisville, (10/10/2016)

Meyer, KS. (Podium presentation).Evaluation and Management of Concussion. Kentucky Coalition of Nurse Practitioners \& Nurse Midwives. (4/25/2015).

Meyer, KS. (Webinar). Understanding Paroxysmal Sympathetic Hyperactivity after Traumatic Brain Injury. Society of Trauma Nurses. (1/21/2015). 
Meyer, KS, Tobe L., \& Boakye M. (Poster). Open visitation in the NeurolCU: a source of distress? Neurocritical Care Society.(10/14).

Meyer, KS. (Podium presentation). Paroxysmal sympathetic hyperactivity in the NeuroICU. Norton Stroke Symposium, Louisville, KY.(9/2014).

Meyer, KS. (Podium presentation). Autonomic storming after traumatic brain injury. Society of Trauma Nursing. Orlando, FL. (3/2014).

Meyer, KS. (Podium presentation).Moderate TBI across the lifespan. Society of Trauma Nursing. Orlando, FL. (3/2014).

Meyer, KS. (Podium presentation).Acute spinal cord injury. Memorial Medical Center Trauma Symposium. Hollywood, FL. (2/2014).

Meyer, KS. (Podium presentation).Visual \& Vestibular Complications of TBI. World Federation of Neuroscience Nurses, Toronto Canada. (3/2009)

Meyer, KS. \& Doncevic, S. Screening for TBI in the military. World Federation of Neuroscience Nurses, Toronto Canada.(3/2009). 